\section{Ruptured pulmonary artery aneurysm, a surgical emergency. A case report and literature review}

\section{Ruptura de aneurisma de la arteria pulmonar, una emergencia quirúrgica. Reporte de caso y revisión de literatura}

A 47-year-old man with no medical history presented to the emergency department complaining of severe sharp chest pain $3 \mathrm{~h}$ lasting, exacerbated with deep inspiration and accompanied by increasing dyspnea.

At first examination, asymmetric thoracic respiratory movements were observed with a diminished expansion of the left side, where inaudible breath sounds were present.

Blood samples were obtained and arterial gases reported $\mathrm{pH} 7.41, \mathrm{PaO}_{2} 63 \mathrm{mmHg}, \mathrm{PaCO}_{2} 21.9 \mathrm{mmHg}, \mathrm{HCO}_{3}$ $16.2 \mathrm{mmol} / \mathrm{L}$, oxygen saturation $93 \%$. Red cell count reported hemoglobin of $7.7 \mathrm{~g} / \mathrm{dl}$ and hematocrit of $24 \%$.

A chest $X$-ray showed an almost fully opacified left hemithorax suggesting a massive left pleural effusion with the ipsilateral lung collapsed and displacement of the trachea toward the right side. Blood was obtained from the thoracentesis.

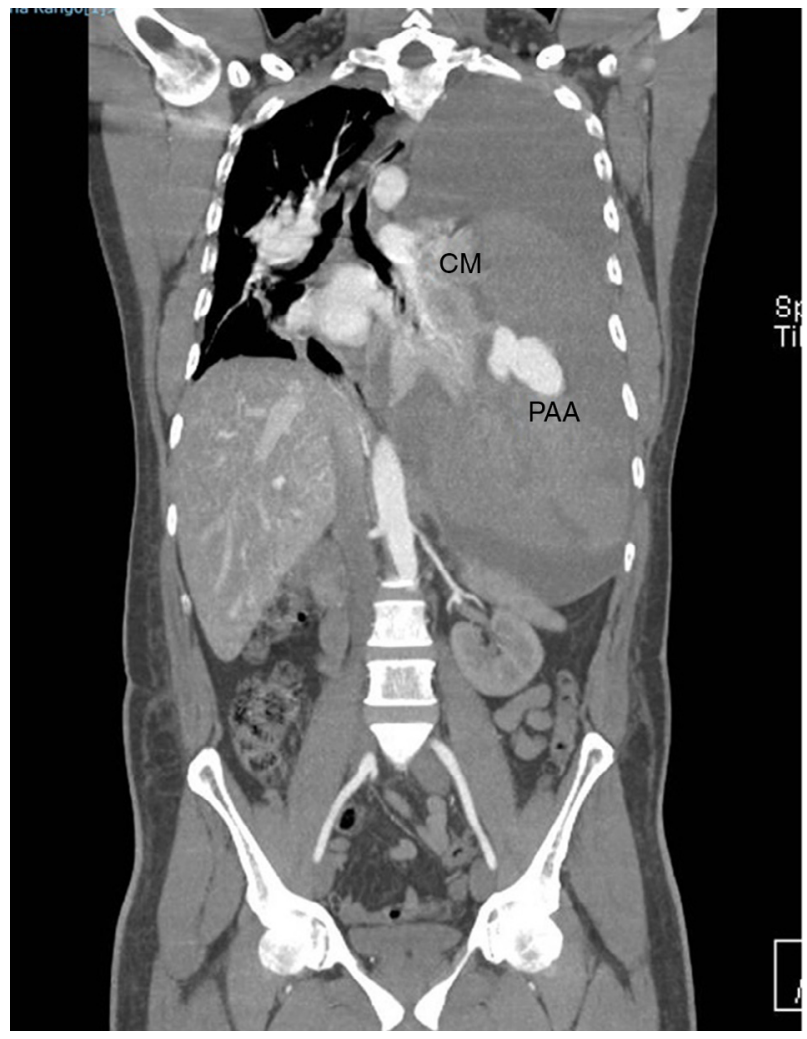

Figure 1 CT angiography in which a left massive hemothorax displaces the mediastinal structures to the contralateral side. An aneurysmal image and extravasation of the contrast media are observed in the left hemithorax. CM, contrast media; PAA, pulmonary artery aneurysm.
A CT-angiography (Fig. 1) was mandatory for a better assessment of the pulmonary vasculature. It showed an image suggesting an aneurysmatic lesion of the left pulmonary artery (Fig. 2).

An invasive approach was decided by means of a posterolateral thoracotomy, where $5000 \mathrm{ml}$ of coagulated blood were obtained. A ruptured aneurysmal lesion of $2 \mathrm{~cm} \times 3 \mathrm{~cm}$ of diameter in the lingular branch of the left pulmonary artery was identified and resected. Lingular lobe resection was also performed.

The patient was admitted to the intensive care unit for further observation, requiring the administration of vasopressors and mechanical ventilatory support. Two weeks after his admission he died because of a nosocomial pulmonary infection.

Pulmonary artery aneurysms (PAAs) are rare and infrequently diagnosed, ${ }^{1-4}$ the best part we know is derived from autopsy findings. ${ }^{5,6}$ They were first described by Bristowe in 1860 at a necropsy ${ }^{5}$ and subsequently by Deterling and Claggett in 1947 who reported eight cases in 109,571 necropsies. ${ }^{2,5}$ However the true incidence is unknown. ${ }^{5}$

An aneurysm is defined as a focal dilation of a blood vessel involving all three layers of the wall., ${ }^{1,3}$ Pseudoaneurysms do not involve all layers of the arterial wall but they pose a higher risk of rupture. ${ }^{7}$ In computed tomography (CT) the upper limit of the main pulmonary artery (PA) diameter in adults is $29 \mathrm{~mm}$ and for interlobar PAs $17 \mathrm{~mm}^{1}$; PAAs are defined as a dilatation greater than $4 \mathrm{~cm}$ in the main PA. ${ }^{8}$

PAAs can be congenital or acquired,,$^{1,5,8}$ in $50 \%$ of the postmortem cases were associated with congenital heart disease, in decreasing order, patent ductus arteriosus, ventricular septal defects and atrial septal defects. ${ }^{1}$ it is presumed that increased flow caused by left-to-right shunt results in hemodynamic shear stress of the vascular wall and promotes aneurysm formation in the PAs. ${ }^{1,8}$

This entity generally affects younger people than aortic aneurysms and there is no sex predilection. ${ }^{1}$ Most of these anomalies affect the main pulmonary artery, ${ }^{7}$ but when they affect the pulmonary artery PA branches, the left PA affection is more common than the right one.

The most frequent association with the formation of PAAs has been pulmonary arterial hypertension, ${ }^{1}$ present in $66 \%$ of cases, which favors the formation of giant aneurysms. ${ }^{4}$ Low-pressure aneurysms seem to have a better prognosis than hypertensive aneurysms. ${ }^{4}$ Chronic pulmonary embolism is a relatively common cause of PAAs, ${ }^{3}$ such aneurysms present mural thickening, webs, and intramural thrombi that can calcify.

Pathophysiological mechanisms involved in PAA formation are limited. Structural changes in elastin and collagen secondary to increased PA pressure that leads to PA dilatation has been proposed. ${ }^{1}$ An abnormal opening of the pulmonary valve or shear stress from a right-to-left shunt may induce apoptosis, remodeling, and aneurysmal transformation of the vessel wall. ${ }^{1,4}$

Among acquired causes the insertion of Swan-Ganz catheters has been a cause of iatrogenic pseudoaneurysms with a $0.2 \%$ incidence of rupture and hemorrhage. ${ }^{1}$ Other iatrogenic causes include chest tube insertion, conventional angiography, surgical resection, biopsy and after penetrating trauma. ${ }^{1}$ Idiopathic PAAs are rare. ${ }^{1,7}$ 

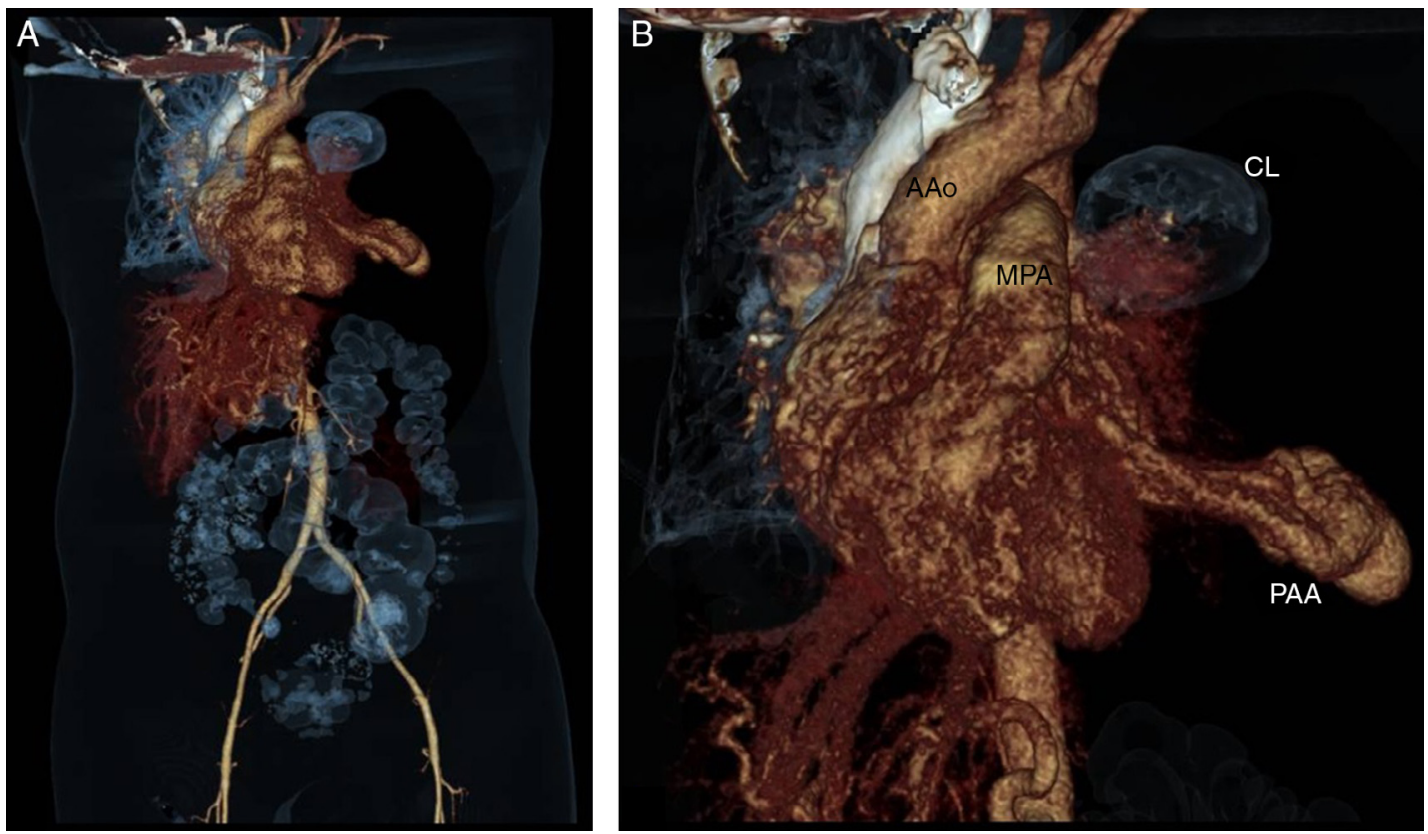

Figure 2 CT angiography 3-D reconstruction (A) and close up image (B) in which the left pulmonary aneurysm and its relationship with other cardiovascular structures are observed. The left pulmonary parenchyma is almost totally collapsed. AAo, ascending aorta; CL, collapsed lung; MPA, main pulmonary artery; PAA, pulmonary arterial aneurysm.

The natural history of the PAAs is poorly understood because of the limited number of cases diagnosed antemortem; however, not all aneurysms progress to the rupture stage. ${ }^{2}$

Most patients with PAAs are asymptomatic or have nonspecific symptoms. ${ }^{9}$ Clinical symptoms include dyspnea, chest pain, hoarseness, palpitations, and syncope. Bronchus compression may produce cyanosis, cough, fever, pneumonia and bronchiectasis. There is an increased risk of pulmonary embolism.

Hemoptysis has been the cause of death in one third of the reported cases and, when present, it should be considered as an indicator of imminent aneurysm rupture, ${ }^{1}$ massive hemoptysis, considered as a loss of more than $300 \mathrm{ml}$ of blood expectorated from the bronchial tree within $24 \mathrm{~h},{ }^{9}$ is an emergency condition that can cause asphyxiation, exsanguination, cardiogenic shock and sudden death.

Pulmonary angiography is the gold standard for establishing the diagnosis of PAAs ${ }^{1,3}$ but, owing to its high spatial resolution, contrast-enhanced multi-detector $C T$ is considered the primary technique for diagnosing PAA, ${ }^{5,7}$ since it allows the evaluation of the size, shape and exact location of the aneurysm, and concomitant structural cardiovascular abnormalities.

The optimal treatment for PAAs remains unclear since there is limited experience because of the low incidence of the disease. ${ }^{1,3}$ Due to the lack of guidelines for its management, patients should be managed individually. ${ }^{6}$

Treatment of PAAs used to be predominantly surgical, however nowadays endovascular techniques like coil embolization, balloon embolization or stent graft placement have been increasingly used, since they are less invasive and produce less damage to the lung parenchyma. ${ }^{10}$

When the main pulmonary trunk is involved, surgical intervention consists of aneurysmectomy or aneurysmorrhaphy. ${ }^{1}$ With peripheral lesions, embolic therapy has been the treatment of choice, instead of lobectomy. ${ }^{10}$

In case of rupture, surgery is the only possible life-saving treatment option. In addition, dissection is an indication for surgery in case of reasonable preoperative morbidity. ${ }^{1,9}$ Surgical outcome is unknown. ${ }^{1}$

In the case of our patient, the first ruptured pulmonary aneurysm related massive hemothorax reported in our country as far as we know, no etiology was identified. The management of the patient, as mentioned before, was individually handled, relying on the information provided by the few reported cases in the literature, since apart of being already recognized as a rare disease, the location of the aneurysm at a peripheral branch of the pulmonary artery is even less frequent. Successful resection of the pulmonary aneurysm and drainage of the massive hemothorax, that required multiple transfusions, were life-saving measures in the acute setting and back the indication of an emergency surgical approach in such patients.

\section{Bibliografía}

1. Kreibich M, Siepe M, Kroll J, et al. Aneurysms of the pulmonary artery. Circulation. 2015;131:310-6.

2. Veldtman GR, Dearani JA, Warnes CA. Low pressure giant pulmonary artery aneurysms in the adult: natural history and management strategies. Heart. 2003;89:1067-70.

3. Serasli E, Antoniadou M, Steiropoulos P, et al. Low-pressure pulmonary artery aneurysm presenting with pulmonary embolism: a case series. J Med Case Rep. 2011;163:1-4.

4. Vistarini N, Aubert S, Gandjbakhch I, et al. Surgical treatment of a pulmonary artery aneurysm. Eur J Cardiothorac Surg. 2007;31:1139-41.

5. Urvinderpal S, Kulbir S, Aditi P, et al. Idiopathic pulmonary artery aneurysm. Indian J Chest Dis Allied Sci. 2014;56:45-7. 
6. Araujo I, Escribano P, Lopez-Gude MJ, et al. Giant pulmonary artery aneurysm in a patient with vasoreactive pulmonary hypertension: a case report. BMC Cardiovasc Disord. 2011;11:1-5.

7. Abdel-Rauf Z, Abdulhamid G. Idiopathic pulmonary artery aneurysm detected with multidetector computed tomography: a rare but potentially lethal vascular abnormality. IMAJ. 2011;13:581-2.

8. Shankarappa RK, Nagaraja DM, Chandrasekaran D, et al. Giant pulmonary artery aneurysm secondary to primary pulmonary hypertension. Texas Heart Inst J. 2010;37:244-5.

9. Senbaklavaci O, Kaneko Y, Bartunek A, et al. Rupture and dissection in pulmonary artery aneurysms: incidence, cause, and treatment-review and case report. J Thorac Cardiovasc Surg. 2001;121:1006-8.

10. Priya J, Sanjiv S, Rajnish J, et al. Transcatheter treatment of pulmonary artery pseudoaneurysm using a PDA closure device. Diagn Interv Radiol. 2011;17:92-4.
Víctor Hugo Contreras-Gutiérrez*, Rodolfo Castaño-Guerra

Departamento de cardiología del Hospital General de México, Ciudad de México, Mexico

* Corresponding author at: Dr Balmis 102, Colonia doctores, delegación Cuauhtémoc, Ciudad de México, CP 06720, Mexico.

E-mail address: victorcontrerasdr@hotmail.es

(V.H. Contreras-Gutiérrez).

http://dx.doi.org/10.1016/j.acmx.2017.01.002

1405-9940/

(c) 2017 Instituto Nacional de Cardiología Ignacio Chávez. Published by Masson Doyma México S.A. This is an open access article under the CC BY-NC-ND license (http: / / creativecommons.org/licenses/ by-nc-nd/4.0/).

\section{Síndrome del seno carotídeo tras endarterectomía carotídea}

\section{Carotid sinus syndrome after carotid endarterectomy}

\section{Introducción}

La endarterectomía carotídea es el tratamiento de elección de los pacientes con estenosis carotídea significativa. La incidencia de bradiarritmias en el postoperatorio precoz es frecuente si bien, estas son transitorias y de buen pronóstico, siendo anecdótica la necesidad de estimulación cardiaca permanente.

El síndrome del seno carotídeo cursa con síncopes con respuesta cardioinhibidora, vasodepresora o mixta. El tratamiento de las formas cardioinhibidoras es el implante de un marcapasos.

Presentamos el caso de un varón que comenzó con síncopes recurrentes en el postoperatorio de endarterectomía carotídea y al que se diagnosticó de síndrome del seno carotídeo.

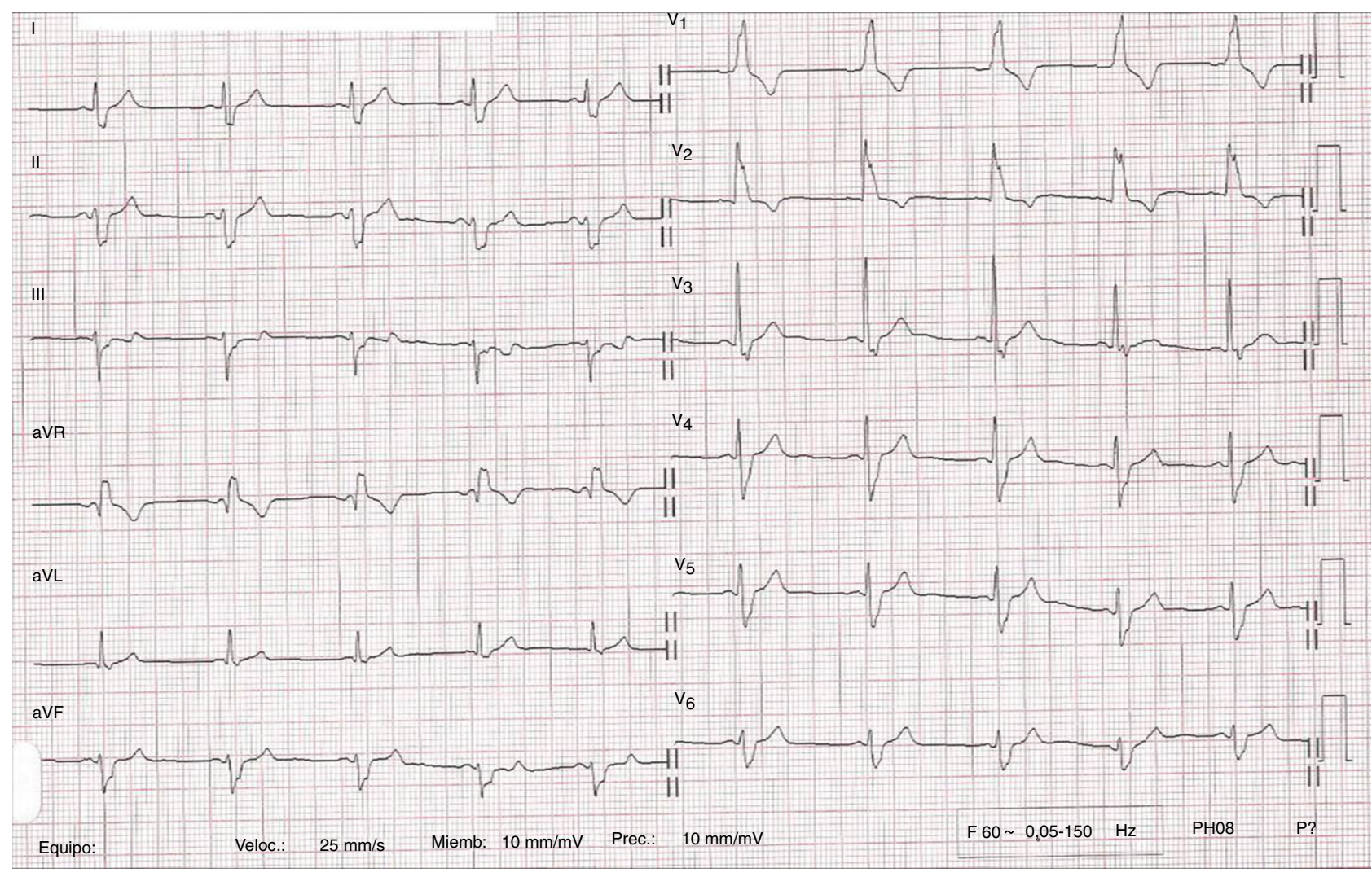

Figura 1 ECG de 12 derivaciones del paciente en el que se comprueba ritmo sinusal con bloqueo bifascicular. 